\title{
Innovaciones de la medicina en la era de la informática
}

\section{Innovations in the field of medicine in the era of informatics}

Julio Sotelo*

Comité de Ética y Transparencia en la Relación Médico-Industria, Ciudad de México, México

En los últimos 100 años, la humanidad ha presenciado grandes progresos en cuanto a procedimientos anestésicos, quirúrgicos, uso de antibióticos, sedantes, antidepresivos, vacunas, hormonas, estudios de imagen, entre incontables avances científicos, los cuales han transformado favorablemente la ancestral tarea de lidiar contra la enfermedad y el sufrimiento. El resultado ha sido dramático: la expectativa de vida del ser humano es superior al doble que la de una centuria atrás, acercándose en promedio a los 80 años en la mayoría de los países con una razonable implementación de servicios médicos.

La secuencia interminable de innovaciones ha producido cambios profundos en el área de la salud y, consecuentemente, en las expectativas de los pacientes respecto a las intervenciones médicas, las cuales actualmente en su mayoría están orientadas a la prevención o transformación del curso de padecimientos ancestrales. Como sería prolongado siquiera enunciarlas, me limitaré a indicar que durante el siglo XX se consolidó la que probablemente será llamada la "época de oro de la medicina".

A la par de los avances médicos, en las últimas décadas los adelantos tecnológicos han transformado a la sociedad entera en forma inesperada. La electricidad, la aviación, el automóvil, la radio, la telefonía, la televisión y la cinematografía son ejemplos de invenciones que han modificado radicalmente la condición humana. En conjunto con las innovaciones en medicina, generaron una nueva época de prosperidad. Si bien se han acompañado de escenarios inéditos, no exentos de riesgos y posibilidades desfavorables, sus beneficios y novedades estructurales se han incorporado a la cotidianidad. Solo por mencionar un ejemplo, la aviación ha traído consigo drásticos cambios sociológicos que han llegado para quedarse y su efecto transformador es ahora inamovible en toda la sociedad, la cual aprovecha sus incontables beneficios e intenta contrarrestar sus ocasionales efectos desfavorables o usos lesivos (como su empleo en conflictos bélicos). Todo este devenir lo hemos denominado "el progreso", miríada de acontecimientos que hemos adoptado y que han modificado nuestra realidad.

Al inicio de la tercera década de este milenio estamos contemplando, con asombro y entusiasmo, el advenimiento tecnológico más revolucionario de los últimos años, quizá el más relevante de este siglo: la implementación incontenible de las técnicas informáticas, que están transformando a toda la sociedad y sus estructuras. Como siempre ha sucedido con los avances tecnológicos de gran envergadura, la medicina será drásticamente modificada por esta revolución tecnológica, tan integral que posiblemente justificará la denominación "era de la informática"; de ser así, la medicina tendrá un antes y un después de ella.

Sin duda, la incorporación de la tecnología informática cambiará todo lo que hace el médico para la sociedad e influirá en su ancestral profesión, dirigiéndola por caminos inéditos e inimaginables hace una o dos décadas. La computación, la telefonía celular y el internet se han integrado a la cotidianidad de la sociedad y su efecto transformador se extiende a la práctica médica; solo es el principio, pero podemos anticipar que seguirá un camino innovador, profundo $y$, en muchos aspectos, impredecible. La ciencia y la ética médica se encargarán de incorporar favorablemente la informática y de neutralizar o limitar sus riesgos; así lo han hecho durante los últimos 100 años con muchas otras tecnologías, ahora imprescindibles. Lo mismo parece que sucederá con las tecnologías de la información, las cuales, sin notarlo, están transformando el
Correspondencia:

*Julio Sotelo

E-mail: jsotelo@unam.mx

0016-3813/@ 2020 Academia Nacional de Medicina de México, A.C. Publicado por Permanyer. Este es un artículo open access bajo la licencia CC BY-NC-ND (http://creativecommons.org/licenses/by-nc-nd/4.0/)
Fecha de recepción: 24-02-2020

Fecha de aceptación: 25-02-2020

.

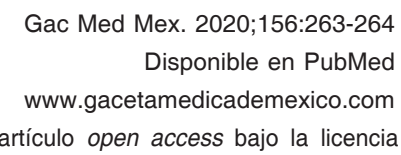
www.gacetamedicademexico.com
artículo open access bajo la licencia 
actuar del médico a niveles inesperados hasta hace poco tiempo. Solo enunciaré, en forma breve y limitada, algunas repercusiones en la ciencia médica.

El teléfono celular ha reforzado la comunicación instantánea entre el médico y el enfermo, lo que no se lograba con la telefonía fija. Ahora, el médico puede ser localizado en todo momento y sin obstáculos por el paciente; los beneficios y potenciales abusos son obvios, pero transformadores en la relación médico-paciente. El nuevo teléfono móvil no solo provee servicio de telefonía, sino también de fotografía, cinematografía, informática, computación, internet y video en tiempo real. En este dispositivo podemos leer, consultar una enciclopedia o un diccionario o buscar información científica comprensiva; incluso, es una fuente de entretenimiento y conocimiento trivial, así como de conexión con las "redes sociales", herramientas democráticas e individualizadas que se han arraigado en la sociedad y que no están exentas de aristas.

Estas "prestaciones" integradas a la telefonía móvil son cuna de novedades modificadoras cuyo solo enunciado llevaría a alongados textos, pero sus efectos serán radicales $y$, por ahora, impredecibles en sus vertientes. Todos sabemos y anticipamos que la revolución informática es un proceso irreversible y que sus efectos también lo serán en la medicina, los médicos y los enfermos.

El advenimiento y la popularización del internet han permitido obtener información científica completa, íntegra, instantánea y en el momento en que se genera; esto no era factible hace pocos años, ni siquiera para los profesionales de la salud que ejercían en las más modernas instalaciones médicas. En la actualidad se puede tener acceso a información científica médica sobre cualquier tema desde cualquier computadora, incluso desde cualquier teléfono móvil. Sin embargo, esta información es accesible para los profesionales de la salud al igual que para cualquier persona que desee consultarla. Novedad con enormes beneficios para la práctica y conocimiento del progreso médico, que se acompaña de múltiples conjeturas sobre el uso de la información, circunstancia también irreversible. El conocimiento médico, particularmente el relativo a las especialidades, hasta hace poco terreno exclusivo de los profesionales de la medicina, se tendrá que acomodar al acceso liberal a la información científica; el dilema será cómo separar la información valiosa de la trivial o redundante o inadecuada o francamente riesgosa.

Arraigada práctica y considerada indispensable en la formación y actualización profesional es la realización periódica de congresos, juntas médicas y sesiones académicas, los cuales también han sido transformados por las ciencias de la información. Las conferencias y sesiones con expertos ahora pueden integrarse y completarse mediante el acceso a internet. La incorporación de esta herramienta de excelencia informática al entrenamiento de los estudiantes de las ciencias médicas - que debe considerar preceptos humanistas, éticos, culturales y de desarrollo psicológico óptimo para los profesionales del futuroes objeto actual de análisis y algoritmos modificadores de los métodos clásicos de enseñanza. Los posibles riesgos y desviaciones son, nuevamente, incontables; los más conspicuos son el aislamiento académico y la tentación de "autoenseñanza" en una disciplina compleja y de múltiples vertientes humanistas, en la cual la adquisición e interpretación de datos si bien son indispensables, constituyen solo una parte del actuar médico integral.

En las próximas décadas será posible reconocer cómo aprovechar íntegramente las ciencias de la información y moderar sus riesgos en la investigación científica y en el tratamiento y prevención de las enfermedades y, más aún, en beneficio de la sociedad. 